\title{
The distal colon provides reserve storage capacity during colonic fluid overload
}

\author{
J Hammer, M Pruckmayer, H Bergmann, K Kletter, A Gangl
}

AKH Wien,

Universitätsklinik für

Innere Medizin IV,

Abteilung für

Gastroenterologie und

Hepatologie,

Währinger Gürtel

18-20, A-1090 Vienna,

Austria

J Hammer

A Gangl

Universitätsklinik für Nuklearmedizin

M Pruckmayer

K Kletter

Institut für

Biomedizinische

Technik und Physik,

Vienna

H Bergmann

Correspondence to:

Dr J Hammer.

Accepted for publication

4 June 1997

\begin{abstract}
Background-In addition to its absorptive function the capacity of the colon to retain fluid might be relevant in compensating for increased fluid loads and prevention of diarrhoea. The distal colon is considered to be mainly a conduit without extensive storage function.

Aims-To evaluate colonic volume capacity in a model of pure osmotic diarrhoea. Methods-A non-absorbable, iso-osmotic solution (OS) containing polyethylene glycol $(500 \mathrm{ml})$ was infused into the caecum of nine healthy volunteers; the control group $(n=5)$ received an equal amount of an easily absorbable electrolyte solution (ES). Fluids were radiolabelled with technetium-99m and gamma camera images were obtained for 48 hours. Counts in the proximal and distal colon were measured and regional and overall colonic transit and stool output were quantified.

Results-After OS, in contrast to ES, faecal output was increased significantly $(p<0.05)$, but colonic transit after OS was not different from transit after ES $(p>0.05)$. This indicates storage of OS in the colon: after OS infusion, counts in the proximal colon decreased linearly while the distal colon stored approximately $30 \%$ of radioactivity for the whole 48 hour study period. After OS, stool output correlated with distal $(p<0.01)$, but not with proximal $(p>0.05)$, colonic transit. In constrast, after ES, stool output was determined by proximal colonic transit $(p<0.05)$ but not by transit through the distal colon ( $p>0.05)$.
\end{abstract}

Conclusion-The distal colon retains nonabsorbable fluid volumes extensively. In our model transit through the distal colon-but not the proximal colondetermined the time at which diarrhoea occurred.

(Gut 1997; 41: 658-663)

Keywords: osmotic diarrhoea; colonic transit; storage capacity; colonic scintigraphy

In healthy humans, 1.5 to 2.0 litres of isotonic chyme which contains water, electrolytes, and organic residues from diet and salivary secretions, reaches the colon each day. ${ }^{12}$ Colonic bacterial metabolism and mucosal absorption reduces this colonic osmotic load and volume $\operatorname{load}^{2-4}$ by more than $90 \%$ so that formed stools contain only 0.1 to 0.2 litres of water per day. ${ }^{1}$ Colonic transit may be an important factor for absorptive capacity, because transit determines the time which is available for metabolic and absorptive processes. Scintigraphic assessment of colonic transit $^{5}$ has demonstrated that under physiological conditions the ascending colon, which is a highly effective absorption site for short chain fatty acids, electrolytes, and water, ${ }^{34}$ and the transverse colon are major sites of storage, whereas the distal colon-the descending and rectosigmoid colonsfunctions mainly as a conduit.

Under pathophysiological conditions, such as in Asiatic cholera ${ }^{7}$ or carbohydrate malabsorption, ${ }^{8}$ flow from the ileum can be increased to as much as 10 litres per day. Up to 6 litres could be absorbed in the colon if infused constantly over a 24 hour period ${ }^{2}$ and an increase in colonic fluid load hastened both transit through the proximal colon and overall colonic transit. ${ }^{9}$ These earlier studies, however, were not designed to assess the relative contributions of colonic transit or absorptive capacity of the colonic mucosa.

The present experiment was designed to assess the role of colonic transit in fluid accommodation. The effect of absorption on fluid accommodation was excluded by using a nonabsorbable fluid containing polyethylene glycol (PEG). ${ }^{10}$ Colonic transit was characterised scintigraphically. Since absorption was inhibited the rate at which radiolabelled substances traversed the colon was only influenced by colonic transit-that is, colonic capacity to store excess fluid. Based on previous experiments ${ }^{129}$ we hypothesised that $500 \mathrm{ml}$ of the PEG solution - but not of a readily absorbable electrolyte solution-would cause diarrhoea by accelerating colonic transit.

\section{Methods}

EXPERIMENTAL SUBJECTS

Studies were carried out in 14 healthy subjects (10 men, four women), aged 19-25 years, who were recruited by public advertisement. None had a history of gastrointestinal disease or abdominal surgery other than appendectomy. Subjects did not take any medication known to alter gastrointestinal motility. Written consent was obtained for the procedure. The protocol was approved by the ethics committee of the Medical Faculty at the University of Vienna.

EXPERIMENTAL PROCEDURE AND GAMMA CAMERA IMAGING

Experiments were carried out according to a previously described protocol. ${ }^{9}$ In brief, volunteers ingested a standard diet for six days. Fibre intake was standardised to $15 \mathrm{~g}$ per day, 
consisting of $60 \%$ water insoluble and $40 \%$ water soluble fibre (according to Anderson and Bridges $^{11}$ ). The diet contained 53\% carbohydrate, $17 \%$ protein, and $30 \%$ fat. On days 1,2 , 5 , and 6 , meals consisted of mixed solid/liquid breakfasts, lunches, and dinners. On day 3, subjects fasted for at least eight hours after lunch; in the night between days 3 and 4, an infusion tube was swallowed. On day 4, no breakfast was eaten.

The orocaecal tube assembly with an outer diameter of $7 \mathrm{~mm}$ consisted of two tubes bonded together with tetrahydrofuran: one radiopaque tube was used to locate the assembly fluoroscopically and to inflate a latex balloon at the tip of the tube that surrounded a mercury weight. The other tube with an inner diameter of $3.5 \mathrm{~mm}$ was used for infusion of the radiolabelled substance. Its distal end was immediately proximal to the latex balloon. When the tip of the tube had left the stomach, the latex balloon was inflated to speed transport of the tube assembly. ${ }^{12}$ As soon as the tip of the tube had reached the caecum the balloon was deflated.

On day 4, starting at $0830 \mathrm{am}, 500 \mathrm{ml}$ of fluid labelled with $1.5 \mathrm{mCi}$ technetium-99mdiethylenetriaminepentaacetic acid (DTPA) was infused within 36 minutes at a rate of $13.9 \mathrm{ml} / \mathrm{min}$. The study group (group A; nine subjects) received a poorly absorbable, isoosmotic, isotonic fluid ${ }^{10}(300 \mathrm{mosm} / \mathrm{l})$ containing $59 \mathrm{~g}$ polyethylene glycol 4000 (PEG), $125 \mathrm{mEq} / 1$ sodium, $10 \mathrm{mEq} / 1$ potassium, $35 \mathrm{mEq} / 1$ chloride, $80 \mathrm{mEq} / 1$ sulphate, and $20 \mathrm{mEq} / \mathrm{l}$ bicarbonate. As a control, we studied five subjects (group B) who received an easily absorbable, isotonic electrolyte solution as described in a previous study $^{9}(145 \mathrm{mEq} / 1$ sodium, $10 \mathrm{mEq} / 1$ potassium, $110 \mathrm{mEq} / 1 \mathrm{chlo}-$ ride, and $45 \mathrm{mEq} / 1$ bicarbonate). Fluid infusion and gamma camera imaging started simultaneously.

A gamma camera (Toshiba, Japan) with a large field of view was used to monitor transit of radiolabelled fluid through the large intestine. Counts were determined at a $140 \mathrm{keV}$ $(20 \%)$ window. For the first hour on day 4, dynamic images with a one minute acquisition time per frame (60 frames per hour) were obtained with the gamma camera in an anterior position. Thereafter, static images (two minutes acquisition time) were taken every 15 to 30 minutes according to a standard protocol for the remainder of day 4 and again on days 5 and 6 -that is, 24,36 , and 48 hours after the start of fluid infusion. Static images were obtained with the gamma camera in both anterior and posterior positions.

EXPERIMENTAL DESIGN

Subjects ate the standardised meals for six days and, starting on day 2, collected each individual stool in separate polyvinyl containers. In the night between days 3 and 4, volunteers swallowed the orocaecal tube and in the morning of day 4 radiolabelled fluids were infused. Thereafter the tube was gently removed. During the first hour after the start of infusion subjects sat on a tilt chair with an angle of $50^{\circ}$; thereafter they were allowed to move. Lunch and dinner were eaten four and eight hours after the start of infusion.

Starting on day 2 all stools were collected in separate containers for 48 hours before infusion and 48 hours after infusion. Four subjects who passed less than $50 \%$ of the radiolabel within the 48 hour period after infusion collected stools for an additional 24 hours. Each stool was weighed and its consistency was described as: formed and solid; semisolid (solid component more than 50\%); semiliquid (liquid component more than $50 \%$ ); or liquid. Gamma camera images of each individual stool were obtained to determine the presence or absence of the radiolabel.

\section{DATA ANALYSIS}

For transit measurements the beginning of fluid infusion was considered as time zero. Data from the obtained scans were stored on an online computer (Toshiba, Japan) for later analysis. Counts were decay corrected to time zero and the geometric mean of the anterior and posterior images was calculated. Using a variable region of interest (ROI) program counts were determined in four different compartments of the colon: caecum plus ascending colon, transverse colon, descending colon, and rectosigmoid colon. Ascending and descending colonic regions were drawn by following the medial border of each region in order to include the hepatic and splenic flexures, respectively. The transverse colon was the sector medial to the flexures. The rectosigmoid region was defined by its junction with the descending colon in the midpelvic region. When radiolabel was detected in the stool, total counts of the scan immediately before the bowel movement were decay corrected for the time delay to the next gamma camera image. Total counts in the colon on the first image after the bowel movement were subtracted from the decay corrected counts and the difference was considered to be the counts in the stool. These and the counts in each colonic region could then be expressed as percentage of total counts. The proximal colon (ProxC) was defined as the combination of ascending plus transverse and the distal colon (DistC) as descending plus rectosigmoid colon.

\section{Segmental colonic transit}

Transit through the proximal and the distal colon was expressed as the percentage of counts that remained in the ProxC and DistC, respectively, at hours $1,4,12,24$, and 48 , and as the mean residence time (MRT) in the colonic compartments. Whereas the percentage of counts that remained in the regions provided an assessment of transit at different points in time, the MRT provided information about transit throughout the whole 48 hour period. MRT was calculated as the area under the curve after plotting the percentage of counts in the region against time using the formula:

$$
\operatorname{MRT}=\Sigma\left(\Delta^{\mathrm{n}} \mathrm{T}_{\mathrm{n}+1} \times 1 / 2\left(\mathrm{cnt}_{\mathrm{n}}+\mathrm{cnt}_{\mathrm{n}+1}\right)\right)
$$

where $\Delta^{\mathrm{n}} \mathrm{T}_{\mathrm{n}+1}$ is the time interval between the two consecutive images $n$ and $n+1,1 / 2\left(\mathrm{cnt}_{n}+\right.$ 
TABLE 1 Stool weight before and after infusion of poorly absorbable osmotic solution (OS) and easily absorbable electrolyte solution (ES)

\begin{tabular}{|c|c|c|c|c|c|c|c|c|c|c|c|c|}
\hline \multirow[b]{3}{*}{ Volunteer } & \multirow{3}{*}{$\begin{array}{l}\text { Solution } \\
\text { infused }\end{array}$} & \multirow{2}{*}{\multicolumn{2}{|c|}{$\begin{array}{l}\text { Stool weight (g) } \\
\text { and number of } \\
\text { stools per day } \\
\text { before infusion }\end{array}$}} & \multicolumn{9}{|c|}{ Weight (g), number and consistency of stools (after infusion) } \\
\hline & & & & \multicolumn{3}{|l|}{ Day 1} & \multicolumn{3}{|l|}{ Day 2} & \multicolumn{3}{|l|}{ Day $3^{b}$} \\
\hline & & Weight & $n$ & Weight & $n$ & Consistency ${ }^{c}$ & Weight & $n$ & Consistency ${ }^{c}$ & Weight & $n$ & Consistency \\
\hline 1 & os & 104 & 1 & 368 & 3 & 1-sl-1 & 222 & 1 & $\mathrm{sl}$ & NA & NA & NA \\
\hline 2 & Os & 89 & 1 & 128 & 1 & 1 & 164 & 1 & ss & 390 & 2 & sl-sl \\
\hline 3 & OS & 195 & 1 & 0 & 0 & NA & 0 & 0 & NA & 710 & 2 & sl-sl \\
\hline 4 & OS & 236 & 1.5 & 272 & 3 & $1-s s-1$ & 402 & 3 & 1-1-ss & NA & NA & NA \\
\hline 5 & Os & 48 & 0.5 & 126 & 2 & $\mathrm{~s}-\mathrm{sl}$ & 322 & 4 & s1-1-1-ss & NA & NA & NA \\
\hline 6 & os & 146 & 1 & 27 & 2 & $1-$ ss & 0 & 0 & NA & 364 & 2 & sl-sl \\
\hline 7 & OS & 68 & 1 & 168 & 2 & 1-ss & 292 & 2 & sl-sl & NA & NA & NA \\
\hline 8 & os & 76 & 1 & 212 & 2 & $\mathrm{~s}-\mathrm{s} 1$ & 276 & 2 & $\mathrm{~s}-\mathrm{sl}$ & NA & NA & NA \\
\hline 9 & Os & 90 & 1 & 380 & 1 & sl & 94 & 1 & sl & NA & NA & NA \\
\hline 10 & ES & 59 & 1 & 54 & 1 & $\mathrm{sl}$ & 131 & 2 & ss-ss & 83 & 1 & $\mathrm{~s}$ \\
\hline 11 & ES & 194 & 1.5 & 252 & 2 & $1-\mathrm{sl}$ & 137 & 2 & $\mathrm{~s}-\mathrm{s}$ & NA & NA & NA \\
\hline 12 & ES & 58 & 0.5 & 108 & 1 & s & 73 & 1 & ss & NA & NA & NA \\
\hline 13 & ES & 32 & 1 & 20 & 2 & 1-sl & 114 & 1 & sl & NA & NA & NA \\
\hline 14 & ES & 245 & 1.5 & 186 & 3 & $1-1-s 1$ & 220 & 3 & $\mathrm{~s}-\mathrm{ss}-\mathrm{s}$ & NA & NA & NA \\
\hline
\end{tabular}

${ }^{\mathrm{a} C a l c u l a t e d ~ f r o m ~} 48$ hour stool collection.

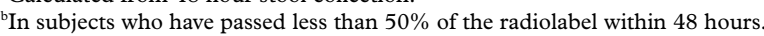

'Consistency is given for each individual bowel movement: s, formed, solid stools; ss, semisolid (solid component more than $50 \%$ ); sl, semiliquid (liquid component $>50 \%$ ); 1 , liquid.

$\left.\mathrm{cnt}_{\mathrm{n}+1}\right)$ is the mean percentage of counts of images $\mathrm{n}$ and $\mathrm{n}+1$ in the region, and $\Sigma$ is the sum of all calculations.

Overall colonic transit

Transit through the whole colon was expressed as the geometric centre (GC) of counts at hours 24 and 48, and as the cumulative percentage of counts excreted in stool. The GC is the weighted average of counts and is an expression of overall colonic transit at any given time..$^{5613}$ For the calculation of the geometric centre each colonic compartment and the stool were assigned rank numbers from 1 (ascending colon) to 5 (stool); the percentage of counts in each region was multiplied by the rank number of this region. The sum was the GC. Thus a low GC implies that most radiolabel is closer to the caecum; a high GC implies that most radiolabel is closer to the stool.

STATISTICAL ANALYSIS

The effects of the infused solutions on colonic transit and stool parameters were compared by Student's $t$ test and Wilcoxon rank test for parametric and non-parametric data, respectively. For analysis of correlation, analyses of

TABLE 2 Parameters of overall colonic transit after infusion of poorly absorbable osmotic solution (OS) and easily absorbable electrolyte solution (ES)

\begin{tabular}{|c|c|c|c|c|c|}
\hline \multirow[b]{2}{*}{ Volunteer } & \multirow{2}{*}{$\begin{array}{l}\text { Solution } \\
\text { infused }\end{array}$} & \multicolumn{2}{|c|}{ Geometric centre of counts at: } & \multicolumn{2}{|c|}{ Cumulative counts in the stools at } \\
\hline & & 24 Hours & 48 Hours & 24 Hours & 48 Hours \\
\hline 1 & OS & 4.45 & 4.54 & 81 & 81 \\
\hline 2 & OS & 2.67 & 3.41 & 5 & 24 \\
\hline 3 & OS & 2.64 & 2.88 & 0 & 0 \\
\hline 4 & OS & 3.59 & 4.90 & 47 & 95 \\
\hline 5 & OS & 2.89 & 4.89 & 31 & 95 \\
\hline 6 & OS & 3.03 & 3.28 & 13 & 13 \\
\hline 7 & OS & 4.52 & 4.71 & 78 & 78 \\
\hline 8 & OS & 3.11 & 4.77 & 36 & 86 \\
\hline 9 & OS & 3.76 & 4.53 & 62 & 81 \\
\hline Mean & OS & 3.4 & 4.2 & 39.2 & 61.4 \\
\hline SEM & & 0.2 & 0.3 & 10.1 & 12.6 \\
\hline 10 & ES & 3.53 & 3.36 & 43 & 43 \\
\hline 11 & ES & 4.99 & 4.99 & 99 & 99 \\
\hline 12 & ES & 2.88 & 4.27 & 0 & 62 \\
\hline 13 & ES & 2.80 & 4.81 & 15 & 95 \\
\hline 14 & ES & 4.73 & 5.00 & 90 & 100 \\
\hline Mean & ES & 3.8 & 4.5 & 49.4 & 79.8 \\
\hline SEM & & 0.5 & 0.3 & 19.7 & 11.6 \\
\hline
\end{tabular}

linear regression were performed between transit parameters and stool. Data are expressed as mean (SEM). A p value of less than 0.05 was considered significant.

\section{Results}

BOWEL MOVEMENTS AFTER INFUSION OF POORLY AND EASILY ABSORBABLE SOLUTIONS

In group A (poorly absorbable fluids) all volunteers developed diarrhoea, defined as a stool weight of more than $250 \mathrm{~g}$ per day, either on day $1(n=4)$ and/or on day $2(n=4)$ or on the third day $(n=3)$ after infusion (table 1$)$. In the six volunteers who passed more than $50 \%$ of counts within 48 hours after infusion (subjects $1,4,5,7,8$, and 9 in table 1) 48 hour stool weight increased by 314 (25) g compared with that before ingestion of the poorly absorbable solution $(p<0.001)$ and stool frequency increased from $2(0.3)$ to $4(0.7)$ per 48 hours $(p<0.05)$. The three volunteers who passed less than $50 \%(0-24 \%)$ of radioactivity during the 48 hours after infusion had no diarrhoea on days 1 and 2 but developed significant diarrhoea with stool weight between 360 and $710 \mathrm{~g}$ on day 3 after infusion. The increase in stool weight after PEG infusion was remarkably constant (313 (38) g) for the two or three day collections (table 1). In all subjects stool consistency was either liquid or semiliquid (more than 50\% liquid component) on the days when diarrhoea occurred.

In group B (easily absorbable fluids) neither stool weight nor stool frequency changed significantly after infusion (table 1 shows individual data). Only one subject (subject 10) had a stool weight that exceeded $250 \mathrm{~g}$ during one of the two 24 hour periods after infusion, although four subjects passed more than $50 \%$ of radioactivity within 48 hours (subjects $11-14$ in table 2). The one subject who passed less than $50 \%$ counts within 48 hours did not develop diarrhoea when the observation period was extended to 72 hours after infusion (table 1). 
Proximal colon

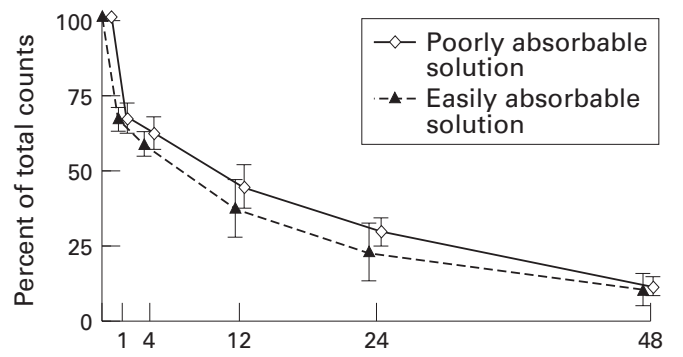

Distal colon

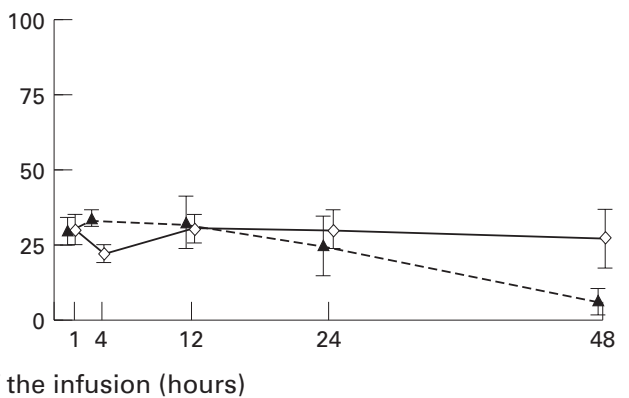

Figure 1: Percentage of total counts (mean (SEM)) that remained in the proximal and distal colon 1, 4, 12, 24, and 48 hours after start of fluid infusion. Counts were decay corrected to time zero.

COLONIC TRANSIT AFTER INFUSION OF POORLY AND EASILY ABSORBABLE SOLUTIONS

Overall colonic transit

Overall colonic transit was similar in both experimental conditions: both the GC of counts and the cumulative counts recovered in the stools did not differ significantly between the two groups (table 2). Counts excreted in stool varied widely among subjects.

\section{Regional colonic transit}

Figure 1 shows the percentage of counts (mean (SEM)) which were retained in the proximal and distal colon plotted against time. In the proximal colon counts decreased to a similar extent over time with both solutions. In the distal colon counts remaining after 48 hours tended to be higher after infusion of the poorly absorbable solution compared with the easily absorbable solution, although this difference was not statistically significant. In addition, there was a decrease in counts retained by the distal colon over the 48 hour observation period after infusion of the easily absorbable solution $(\mathrm{p}<0.05)$ whereas distal colonic counts after the poorly absorbable solution did not change over the 48 hour period.

The MRTs in the proximal colon were not different between group A (16.4 (2.0) hours) and group B (15.8 (3.4) hours) $(p=0.76)$. MRT in the distal colon tended to be higher in group A (15.1 (2.7) hours) compared with group B (10.6 (3.3) hours); however, this difference also did not reach significance $(\mathrm{p}=0.41)$.

For the distal colon, MRTs were calculated for the descending and the rectosigmoid colon separately: MRT in the descending colon was 557 (124) hours in group A and 289 (70) hours in group $B(p>0.05)$; MRT in the rectosigmoid

TABLE 3 Correlation between stool weight and segmental colonic transit, assessed by MRT, in the distal and proximal colon, and overall colonic transit, assessed by geometric centre after 24 and 48 hours

\begin{tabular}{|c|c|c|c|c|}
\hline & \multicolumn{2}{|c|}{ Group A (osmotic solution) } & \multicolumn{2}{|c|}{ Group B (electrolyte solution) } \\
\hline & $r$ & $p$ & $r$ & $p$ \\
\hline \multicolumn{5}{|l|}{ Regional colonic transit } \\
\hline MRT (DistC) $v 48 \mathrm{~h}$ stool weight & -0.88 & $<0.01$ & -0.74 & $>0.05$ \\
\hline $\begin{array}{l}\text { MRT (ProxC) v } 48 \mathrm{~h} \text { stool weight } \\
\text { Overall colonic transit }\end{array}$ & -0.63 & $>0.05$ & -0.96 & $<0.05$ \\
\hline GC $(24 \mathrm{~h}) v 24 \mathrm{~h}$ stool weight & 0.67 & $<0.05$ & 0.89 & $<0.05$ \\
\hline GC $(48 \mathrm{~h}) v 48 \mathrm{~h}$ stool weight & 0.92 & $<0.001$ & 0.56 & $>0.05$ \\
\hline
\end{tabular}

Correlation coefficient $(r)$ and $\mathrm{p}$ values $(\mathrm{p})$ for the regression between stool weight and segmental colonic and overall colonic transit, respectively. colon was 317 (46) hours and 357 (134) hours in groups $A$ and $B(p>0.05)$, respectively.

CORRELATION BETWEEN STOOL WEIGHT AND COLONIC TRANSIT

Regional colonic transit

After the poorly absorbable solution there was a significant negative correlation between MRT (DistC) and 48 hour stool weight with an $r$ value of $-0.88(\mathrm{p}<0.001)$ (table 3 , fig 2$)$. There was no correlation between MRT (DistC) and 48 hour stool weight after the saline control $(r=-0.74 ; \mathrm{p}=0.15)$. The correlation between MRT (ProxC) and 48 hour stool weight was only significant for the electrolyte solution $(r=-0.96, \mathrm{p}<0.05)$ but not for the poorly absorbable solution $(r=-0.63, \mathrm{p}=0.07)$.

When we divided the distal colon for further analysis into descending and rectosigmoid colon, there was a significant negative correlation between 48 hour stool weight and both MRT in the descending colon $(r=-0.90$, $\mathrm{p}<0.001)$ and the rectosigmoid colon $(r=-$ $0.70, \mathrm{p}<0.05)$ after the poorly absorbable solution. After the electrolyte solution, no such correlation was found (descending colon: $r=-0.79, \mathrm{p}=0.17$; rectosigmoid colon: $r=0.64$, $\mathrm{p}=0.24)$.

\section{Overall colonic transit}

We also calculated the correlation between GC and stool weight after 24 and 48 hours, respectively: after the poorly absorbable solution

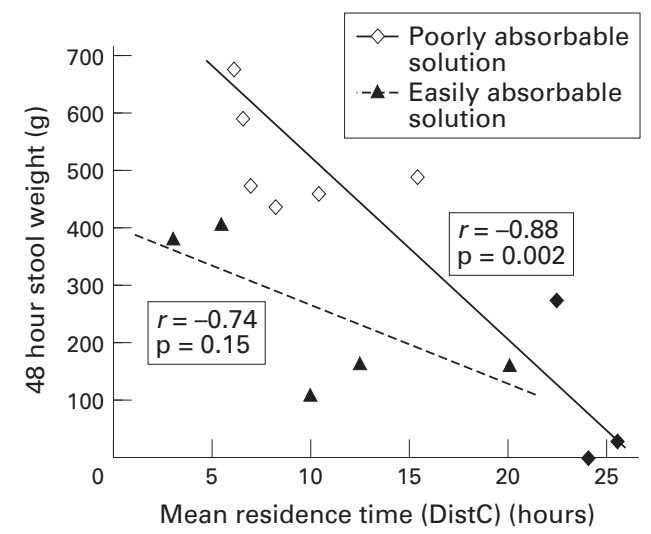

Figure 2: Relation between mean residence times in the distal colon, determined at 48 hours, and 48 hour stool weight after caecal infusion of poorly absorbable osmotic solution and easily absorbable electrolyte solution. The filled diamonds identify the three subjects with delayed diarrhoea (subjects 2, 3, and 6 in table 2). 
there was a significant correlation between GC and stool weight after 24 hours $(r=0.67$; $\mathrm{p}<0.05)$ and an even better correlation after 48 hours $(r=0.92 ; \mathrm{p}<0.001)$. In contrast, after the electrolyte solution there only was a significant correlation between GC and stool weight after 24 hours $(r=0.89 ; \mathrm{p}<0.05)$, but not after 48 hours $(r=0.56 ; \mathrm{p}>0.05)$.

\section{Discussion}

Our study showed that total colonic transit is not influenced by the absorbability of colonic fluid and that the distal colon-especially the descending colon - may have reserve capacity which can accommodate intracolonic fluid which was not absorbed in more proximal parts of the colon. Residence time of colonic contents may be an important factor which provides the time which is necessary for mucosal absorption of fluid to take place. In patients with diarrhoea who have increased fluid volumes entering the colon, the severity of rectal fluid loss may therefore not only be reduced by reserve absorptive capacity of the colonic mucosa ${ }^{12}$ but also by slowing of colonic transit.

Our study was designed to assess the influence of a caecal fluid load on colonic transit; radioactive markers were used to label colonic contents. In one arm of the study an easily absorbable electrolyte solution was used for caecal infusion. Our results showed that the colon was able to salvage $500 \mathrm{ml}$ of electrolyte solution which was infused within 36 minutes since no significant diarrhoea developed. It is safe to assume that no significant diarrhoea would have developed after the end of the 48 hour observation period as almost $80 \%$ of the infused radioactivity had appeared in the stool after 48 hours. The design of this part of our study does not allow a conclusion as to whether most or all of this salvage took place in the right colon or whether it also took place in more distal parts of the colon. In a previous study where increasing fluid loads were infused into the caecum, ${ }^{9}$ however, proximal colonic transit was hastened by higher volumes. The descending colon acted mainly as a conduit and fluids were stored extensively in the rectosigmoid colon. ${ }^{9}$

Although after caecal infusion of the electrolyte solution the increases in stool frequency and changes in stool weight were not statistically significant in our small group of subjects, analysis of individual data showed that overall colonic transit correlated significantly with stool weight 24 hours after infusion. In addition, regional transit through the proximal colon, but not the distal colon, was also significantly correlated with stool weight. Whether these correlations were influenced by the infused volume or whether they also exist under normal circumstances cannot be determined by our data. Moreover, we cannot exclude that the lack of statistical significance of correlation between distal colonic transit and stool weight was due to the small number of observations. However, in patients with diarrhoea predominant irritable bowel syndrome, an accelerated proximal colonic transit is an important determinant of stool weight. ${ }^{14}$
In addition, with lactulose, a fermentable osmotic laxative, the acceleration of proximal colonic transit parallels the acceleration of overall colonic transit and the increase in faecal output. ${ }^{15}$

In the second arm of our study the effect of mucosal absorption was excluded by using a poorly absorbable PEG solution. Therefore, in contrast to the electrolyte solution, the volume of caecally infused PEG solution could not be reduced during its passage through the colon. Significant diarrhoea developed as a result. As we did not measure faecal PEG we do not know the time course of PEG excretion, but it is safe to assume that stool output paralleled faecal PEG output. Interestingly, although the effects of the electrolyte solution and PEG solution on stool output were so different, there were no significant differences between the effects on regional and total colonic transit when the groups of subjects were compared. The tendencies for prolonged transit through the distal colon and for a prolonged mean residence time in the descending colon after caecal infusion of the PEG solution were not statistically significant.

When individual data were analysed, subjects with PEG infusion had a significant correlation between overall colonic transit and stool weight after 24 and 48 hours. When we looked at the correlation between regional colonic transit and stool weight, significant differences in the effects of the PEG solution compared with the electrolyte solution could be observed. In contrast to the electrolyte solution, after the PEG solution there was no correlation between proximal colonic transit and stool weight, but there was a significant correlation between stool weight and distal colonic transit.

There were large interindividual differences in 48 hour stool weights after infusion of PEG. Three of the subjects $(2,3$, and 6$)$ even had lower 48 hour stool weights than were observed after infusion of the electrolyte solution. These subjects had delayed diarrhoea that occurred between 48 and 72 hours after the infusion. It is mainly due to these subjects that a significant correlation between distal colonic transit and 48 hour stool weight was observed. It cannot be excluded that these three subjects represent a subgroup which reacts differently - that is, with a more pronounced slowing of distal colonic transit than the rest of the PEG subjects; this hypothesis must be investigated in future studies.

Our data show that after caecal infusion of an absorbable fluid transit through the proximal colon is correlated with stool weight. This suggests that residence time in the proximal colon plays a significant role in colonic absorptive capacity. Transit through the proximal colon is not influenced by the absorbability of the infused fluid which suggests that at the infusion rate in our study transit is not stimulated by persistingly elevated caecal or right colonic volume. Our data further show that if intracolonic fluids which cannot be absorbed in the proximal colon reach the distal part of the colon, the distal colon can provide reserve 
storage capacity, at least in some subjects, which should allow additional mucosal absorption to take place. This is suggested by the significant correlation between regional transit through the distal colon and severity of diarrhoea after caecal infusion of PEG solution.

After the infusion of poorly absorbable solution, counts in the distal colon stayed at a plateau of approximately $30 \%$ of total counts for 48 hours, independent of the counts that were recovered in the stool (fig 2); this would suggest a volume of approximately $150 \mathrm{ml}$ of infusate remained in the distal colon for 48 hours.

In our study unabsorbability was due to the chemical composition of the infused fluid. Our model is directly applicable to osmotic types of diarrhoea, such as in severe cases of carbohydrate malabsorption ${ }^{4}{ }^{16}$ or after ingestion of magnesium. ${ }^{18}$ In addition, we assume that our results may also apply to diarrhoeal diseases in which up to 10 litres of fluid may reach the colon $^{78}$ if the proximal colon is overwhelmed by the fluid load and increased volumes of fluid reach the distal parts of the colon.

Diarrhoea can be due to the failure of the colon to salvage its contents. ${ }^{19}$ Thus failure could be due either to an increase in the volume or a change in the composition of the substrate entering the colon. Another possible reason would be an altered motility that does not provide optimal conditions for storage and absorption. Alterations of colonic motility associated with a failure of colonic salvage have been described in patients with functional bowel disorders, ${ }^{14}{ }^{20-22}$ ulcerative colitis, ${ }^{23}$ and faecal incontinence. ${ }^{24}$ The role of the distal colon in these and other diarrhoeal conditions requires further study.

This study was supported by a grant from the Fonds zur wissenschaftlichen Forschung (FWF) (10109-MED), Vienna, Austria. We thank Dr H F Hammer for his help in preparing the manuscript.

1 Phillips SF, Giller J. The contribution of the colon to electrolyte and water conservation in man. $f$ Lab Clin Med 1973; 81: 733-46.

2 Debongnie JC, Phillips SF. Capacity of the human colon to absorb fluid. Gastroenterology 1978; 74: 698-703.

3 Ruppin H, Bar-Meir S, Soergel KH, Wood CM, Schmitt MG Jr. Absorption of short chain fatty acids by the colon. Gastroenterology 1980; 78: 1500-7.
4 Hammer HF, Fine KD, Santa-Ana CA, Porter JL, Schiller LR, Fordtran JS. Carbohydrate malabsorption. Its measurement and its contribution to diarrhoea. F Clin Invest 1990; 86: 1936-44.

5 Krevsky B, Malmud LS, D'Ercole F, Maurer AH, Fisher RS. Colonic transit scintigraphy. A physiologic approach to the quantitative measurement of colonic transit in humans. Gastroenterology 1986; 91: 1102-12.

6 Proano M, Camilleri M, Phillips SF, Brown ML, Thomforde GM. Transit of solids through the human colon: regional quantification in the unprepared bowel. $A m \dot{f}$ Physiol 1990; 258: G856-62.

7 Banwell JG, Pierce NF, Mitra RC, Brigham KL, Caranasos GJ, Keimowitz RI, et al. Intestinal fluid and electrolyte transport in human cholera. F Clin Invest 1970; 49: 183-5.

8 Flourié B, Briet F, Florent Ch, Pellier P, Maurel M Rambaud J-C. Can diarrhoea induced by lactulose be reduced by prolonged ingestion of lactulose? Am f Clin Nutr 1993; 58: 369-75.

9 Hammer J, Phillips SF. Fluid loading of the human colon: effects on segmental transit and stool composition. Gastroenterology 1993; 105: 988-98.

10 Davis GR, Santa Ana CA, Morawski SG, Fordtran SF. Development of a lavage solution associated with minimal
water and electrolyte absorption or secretion. Gastroenterolwater and electrolyte

11 Anderson JW, Bridges SR. Dietary fiber content of selected foods. Am f Clin Nutr 1988; 47: 440-7.

12 Kerlin P, Tucker R, Phillips SF. Rapid intubation of the ileocolonic region in man. Aust NZ F Med 1983; 13: 591-3.

13 Miller MS, Galligan JJ, Burks TF. Accurate measurement of intestinal transit in the rat. F Pharmacol Methods 1981; 6: 211-7.

14 Vassallo M, Camilleri M, Phillips SF, Brown ML, Chapman NJ, Thomforde GM. Transit through the proximal colon influences stool weight in the irritable bowel syndrome. influences stool weight in the ir

15 Barrow L, Steed KP, Spiller RC, Watts PJ, Melia CD, Davis MC, Wilson CG. Scintigraphic demonstration of lactuloseinduced accelerated proximal colon transit. Gastroenterology 1992; 103: 1167-73.

16 Hammer HF, Santa-Ana CA, Schiller LR, Fordtran JS. Studies of osmotic diarrhoea induced in normal subjects by ingestion of polyethylene glycol and lactulose. $\mathcal{F}$ Clin Invest 1989; 84: 1056-62.

17 Ameen VZ, Powell GK, Jones LA. Quantification of faecal carbohydrate excretion in patients with short bowel syndrome. Gastroenterology 1987; 92: 493-500.

18 Fine KD, Santa-Ana CA, Fordtran JS. Diagnosis of magnesium-induced diarrhoea. $N$ Engl $尹$ Med 1991; 324: magnesi

19 Read NW. Diarrhoea: the failure of colonic salvage. Lancet 1982; ii: 481-3.

20 Connell AM. The motility of the pelvic colon. Part II. Paradoxical motility in diarrhoea and constipation. Gut 1962; 3: 342-8.

21 Frexinos J, Fioramonti J, Bueno L. Colonic myoelectrical activity in IBS painless diarrhoea. Gut 1987; 28: 1613-8.

22 Bazzocchi G, Ellis J, Villanueva-Meyer J, Reddy SN, Mena I, Snape WJ Jr. Effect of eating on colonic motility and transit in patients with functional diarrhoea. Simultaneous scintigraphic and manometric evaluations. Gastroenterology 1991; 101: 1298-306.

23 Reddy SN, Bazzocchi G, Chan S, Akashi K, VillanuevaMeyer J, Yanni G, et al. Colonic motility and transit in health and ulcerative colitis. Gastroenterology 1991; 101: 1289-97.

24 Read NW, Haynes WG, Bartolo DC, Hall J, Read MG, Donnelly TC, Johnson AG. Use of anorectal manometry during rectal infusion of saline to investigate sphincter function in incontinent patients. Gastroenterology 1983; 85: 105-13. 